\title{
Experimental Study of Stabilized Soil Utilizing Circulating Fluidized Bed Combustion Desulfurization Ash with Carbide Slag and Desulfurization Gypsum
}

\author{
Dezhi Shao, ${ }^{1}$ Jinlong Liu, ${ }^{2}$ and Xin Huang ${ }^{1}$ \\ ${ }^{1}$ School of Transportation Science and Engineering, Beihang University, Beijing 100191, China \\ ${ }^{2}$ Beijing Zhongyandadi Engineering Technology Co., Ltd., Beijing 100191, China \\ Correspondence should be addressed to Dezhi Shao; sdzccc@126.com
}

Received 30 September 2015; Accepted 1 December 2015

Academic Editor: Yuanxin Zhou

Copyright ( $\odot 2015$ Dezhi Shao et al. This is an open access article distributed under the Creative Commons Attribution License, which permits unrestricted use, distribution, and reproduction in any medium, provided the original work is properly cited.

This paper discusses the feasibility of preparing soil stabilizer which is circulating fluidized bed combustion ash-based, supplemented with carbide slag and desulfurization gypsum, composed entirely of complete industrial wastes. The results show that CFBC ash has better pozzolanic activity than fly ash. When stabilizer total content is $10 \%$ and the ratio of CFBC ash : carbide slag : desulfurization gypsum is $7.2: 1.8: 1$, compressive strength of stabilized soil can reach the maximum of $2.12 \mathrm{MPa}$ at the age of $28 \mathrm{~d}$ of curing. Stabilizer can meet the strength requirements of cement-soil mixing pile composite foundation and cement-soil mixing pile waterproof curtain.

\section{Introduction}

With the increasing amount of coal mined and gangue heaped, countries encourage utilizing the combustion of gangue and low calorific value coal to generate power and ban permanent gangue heap. Circulating fluidized bed combustion (CFBC) is widely used due to the ability of utilizing low calorific value coal, fully combust, and high desulfurization efficiency [1]. Circulating fluidized bed combustion ash (CFBC ash) is the main product of the coal combustion, which increases year by year. But the resource utilization of CFBC ash is still in infancy. Compared with pulverized fuel fly ash (PFA), CFBC ash is various in chemical compositions, higher water requirement, richer in anhydrite and free lime, which seriously limits the resource utilization [2]. Approximately 50 million tons of CFBC ash is generated annually in China. However, large quantity of raw CFBC ash in China is mainly discharged directly to waste dumps [3]. With the rapid development of modern industry, production of industrial wastes increases year by year. In 2013, the production of carbide slag (CS) was 22.11 million tons; the production of flue gas desulfurization gypsum (FGDG) was 75.50 million tons. Although the comprehensive utilization rate of industrial wastes is improving gradually in recent years, there are still masses of industrial wastes that have not been utilized. Unutilized industrial wastes occupy a great amount of land. Soluble harmful elements contained in industrial wastes may also cause groundwater pollution. A long period of air storage causes lots of dust flow in the air, which may generate air pollution. Problems mentioned above lead to heavy economic and environmental burden to the country [4].

Taking advantage of the hydration characteristic of industrial wastes to produce soil stabilizer is one of the most important ways to recycle industrial wastes. Research shows that stabilizer can be prepared with entirely industrial wastes (like gangue, CS, and phosphor gypsum); the $28 \mathrm{~d}$ compressive strength of stabilized soil can reach $2 \mathrm{MPa}$ and can be 3 times higher compared to that stabilized by cement in the same content [5]. The compressive strength of CFBC ash stabilizing soil can meet the strength requirement of highway subgrade [6-8]. But researches and reports on utilizing CFBC ash to stabilize soil under natural water content are rare.

Research shows that the structure of clay is formed by soil particle groups integrated with clay particles and holes inside [9]. Some kinds of stabilizers (e.g., cement) can only produce cementitious hydrates, like calcium silicate hydrates (CSH), 
TABLE 1: Physical mechanical properties of tested soil.

\begin{tabular}{lcccccc}
\hline \multirow{2}{*}{ Soil sample } & \multicolumn{7}{c}{ Physical properties } \\
& $W / \%$ & $G_{S}$ & $e$ & $S_{r}$ & $\omega_{L}$ & $\omega_{p}$ \\
\hline ST & 20.40 & 2.61 & 0.66 & 0.89 & 0.259 & 0.167 \\
\hline
\end{tabular}

Notes: $W$ : water content; $G_{S}$ : specific gravity; $e$ : natural void ratio; $S_{r}$ : saturation; $\omega_{L}$ : liquid limit; $\omega_{p}$ : plastic limit.

which cannot fill pores among the particles efficiently; as a result, it will limit the increase of strength. Soil stabilizer which can produce cementitious hydrates and expansible hydrates has better reinforcement effect than that which can only produce cementitious hydrates. Cementitious hydrates can wrap and bind loose soil particles, and expansible hydrates can squeeze and fill the pores. Combining both cementitious hydrates and expansible hydrates will lead to better reinforcement effect. CFBC ash has certain pozzolanic activity to produce cementitious hydrates $\mathrm{CSH}$. Free lime, activated $\mathrm{Al}_{2} \mathrm{O}_{3}$, and anhydrite in CFBC ash can produce volume expansion. Consequently, we can take advantage of those characters to prepare soil stabilizer with CFBC ash. The aim of this work is to discuss the feasibility of preparing soil stabilizer which is CFBC ash-based, supplemented with CS and FGDG, composed of complete industrial wastes.

\section{Experimental}

2.1. Materials. Soil sample: the soil sample (ST) was taken from Nanhai Park in Taiyuan City, Shanxi Province. The physical properties of the soil sample are presented in Table 1.

CFBC fly ash was retrieved from Shanxi thermal power plant. The $80 \mu \mathrm{m}$ and $45 \mu \mathrm{m}$ sieving residue of CFBC ash processed by crushing equipment is $0.8 \%$ and $8.8 \%$, respectively. The PFA was retrieved from Tangshan thermal power plant. The $80 \mu \mathrm{m}$ and $45 \mu \mathrm{m}$ sieving residue of PFA processed by crushing equipment is $0.1 \%$ and $2.9 \%$, respectively. The $\mathrm{XRD}$ patterns of the CFBC fly ash is shown in Figure 1. From Figure 1, it is clear to see that the CFBC fly ash is composed mainly of amorphous substances and a certain amount of quartz, limestone, and other crystalline material compositions.

CS was retrieved from Tianjin acetylene plant, the desulfurization gypsum was retrieved from Guizhou Hongfu Industrial Development General Co., Ltd. Chemical compositions of raw materials are shown in Table 2.

\subsection{Experimental Methods and Procedures}

(1) Weigh stabilizer and water according to the mix proportions, then put them into the agitator kettle, and mix them by electrical mixing machine for $60 \mathrm{sec}-$ onds.

(2) Weight soil according to the proportion, put it into the agitator kettle, mix it at low speed for 30 seconds, and then mix it at high speed for 60 seconds.

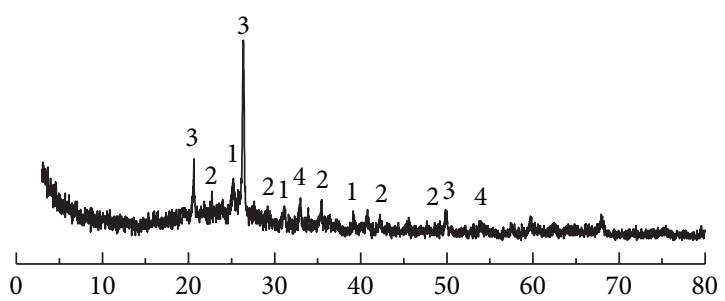
(1) Anhydrite
(3) Quartz
(2) Limestone
(4) Hematite

FIgURE 1: XRD patterns of CFB ash.

TABLE 2: Chemical compositions of raw materials.

\begin{tabular}{lcccccc}
\hline Compositions/\% & $\mathrm{SiO}_{2}$ & $\mathrm{Al}_{2} \mathrm{O}_{3}$ & $\mathrm{CaO}$ & $\mathrm{SO}_{3}$ & $\mathrm{Fe}_{2} \mathrm{O}_{3}$ & Others \\
\hline CFBC ash & 50.11 & 28.26 & 8.85 & 3.99 & 4.72 & 4.07 \\
PFA & 48.18 & 37.88 & 3.42 & 1.52 & 4.22 & 4.78 \\
CS & 2.84 & 2.16 & 68.99 & 0.76 & 0.15 & 25.10 \\
FGDG & 3.61 & 0.13 & 31.30 & 42.70 & 0.02 & 22.24 \\
\hline
\end{tabular}

Notes: self-made admixture LLY is a kind of inorganic liquid. The LLY content is $0.5 \%$ of stabilizer by weight.

(3) Use scraper to scrape the stabilized soil pasted on wanes and wall into the agitator kettle, continuing to mix for 60 seconds.

(4) Compact the soil-admixture samples into steel molds with $50 \mathrm{~mm} \times 50 \mathrm{~mm} \times 50 \mathrm{~mm}$ in three layers; then, molds were vibrated for $60 \mathrm{~s}$ on jolting table (ZT- $1 \times$ $1)$.

(5) Demold after compaction for 24 hours, then move the samples into standard curing chamber with curing temperature $20^{\circ} \mathrm{C} \pm 2$ and curing humidity $95 \%$.

The compressive strength tests of the samples were conducted according to Chinese standard test methods of soils for highway engineering (JTJ051-93). Three specimens of each mixture were tested to investigate the average compressive strength.

\section{Results and Discussion}

Table 3 shows the mix proportions and the compressive strength of stabilized soil samples at $28 \mathrm{~d}$. The mixing proportion ratios of different materials were relative to the total weight of stabilized soil. Total mixing proportion of stabilizer is $10 \%$. The liquid/stabilizer ratio is kept at a constant 1.0 . Proportions of control groups 2-1 and 2-2 are based on the optimum proportion from previous studies [10].

3.1. Comparison of Pozzolanic Activity between CFBC Ash and PFA. As shown in Table 3, comparing the compressive strength of samples 1-2, 1-3, and 1-4 and 2-1 and 2-2, using $\mathrm{CFBC}$ ash to prepare stabilizer, has better reinforcement effect than using PFA. The compressive strength of CFBC ash stabilizing soil at $28 \mathrm{~d}$ is $3-5$ times PFA stabilizing soil. Although the particle size of CFBC ash is larger than PFA, the 
TABLE 3: Stabilizer components and stabilized soil strength.

\begin{tabular}{lccccc}
\hline Mixture & $\begin{array}{c}\text { CFBC ash } \\
(\%)\end{array}$ & $\begin{array}{c}\text { CS } \\
(\%)\end{array}$ & $\begin{array}{c}\text { PFA } \\
(\%)\end{array}$ & $\begin{array}{c}\text { FGDG } \\
(\%)\end{array}$ & $\begin{array}{c}\text { Compressive } \\
\text { strength (MPa) }\end{array}$ \\
\hline $1-1$ & 5 & 5 & & & 0.69 \\
$1-2$ & 6 & 4 & & & 0.75 \\
$1-3$ & 7 & 3 & & & 0.87 \\
$1-4$ & 8 & 2 & & & 1.04 \\
$1-5$ & 9 & 1 & & & 0.66 \\
\hline $2-1$ & & 2 & 8 & & 0.22 \\
$2-2$ & & 1 & 9 & & 0.21 \\
\hline $3-1$ & 7.2 & 1.8 & & 1 & 2.12 \\
$3-2$ & 6.4 & 1.6 & & 2 & 1.70 \\
$3-3$ & 5.6 & 1.4 & & 3 & 1.45 \\
$3-4$ & 4.8 & 1.2 & & 4 & 1.03 \\
\hline
\end{tabular}

compressive strength of CFBC ash stabilizing soil is higher than PFA ash stabilizing soil, indicating that CFBC ash has better pozzolanic activity than fly ash.

Most of PFA particles are dense and smooth. By contrast, CFBC ash is mainly composed by coarse and irregular particles, which are more favorable to perform the pozzolanic activity [11]. Based on the character of the reaction products of active $\mathrm{SiO}_{2}, \mathrm{Al}_{2} \mathrm{O}_{3}$ and lime are soluble in low concentration hydrochloric acid; experiments show that the reaction rate constant of CFBC ash is higher than PFA [12]. Mixing CFBC ash and PFA into cement clinker, respectively, the results show that the compressive strength of CFBC ash-cement clinker is distinctly higher than PFA-cement clinker. All the results agree that $\mathrm{CFBC}$ ash has better pozzolanic activity than fly ash.

3.2. The Optimum Proportion between CFBC Ash and CS. As shown in Table 3, there is an optimum proportion utilizing CFBC ash and CS to stabilize soil. The highest compressive strength of CFBC ash stabilizing soil at $28 \mathrm{~d}$ is $1.04 \mathrm{MPa}$, and the optimum proportion is CFBC ash : $\mathrm{CS}=8: 2$ by weight.

$\mathrm{CFBC}$ ash is various in chemical compositions; hence, lots of experiments would be done to research the optimum proportion between CFBC ash and CS. To reduce the workload, in this paper, put forward an equation to estimate the optimum proportion between CFBC ash and CS.

Assume that the main hydration product $\mathrm{CSH}$ is formed with $\mathrm{CaO} / \mathrm{SiO}_{2}$ molar ratio at 1.2. The reaction is shown as follows:

$$
1.2 \mathrm{CaO}+\mathrm{SiO}_{2}+n \mathrm{H}_{2} \mathrm{O} \longrightarrow 1.2 \mathrm{CaO} \cdot \mathrm{SiO}_{2} \cdot n \mathrm{H}_{2} \mathrm{O}
$$

Active $\mathrm{Al}_{2} \mathrm{O}_{3}$ and $\mathrm{Fe}_{2} \mathrm{O}_{3}$ react with $\mathrm{CaO}$ to form $\mathrm{C}_{3}(\mathrm{~A}, \mathrm{~F}) \mathrm{H}_{6}$ which reacts with $\mathrm{CaSO}_{4} \cdot 2 \mathrm{H}_{2} \mathrm{O}$ to form ettringite (AFt). The proportion is calculated by the following equation:

Unit mass $\mathrm{SiO}_{2}$ hydration reaction needs unit mass:

$$
\mathrm{CaO}=1.2 \times \frac{56}{60}=1.12
$$

Unit mass $\mathrm{Al}_{2} \mathrm{O}_{3}$ hydration reaction needs unit mass:

$$
\mathrm{CaO}=\frac{168}{102}=1.65
$$

Unit mass $\mathrm{Fe}_{2} \mathrm{O}_{3}$ hydration reaction needs unit mass:

$$
\mathrm{CaO}=\frac{168}{160}=1.05 .
$$

Unit mass $\mathrm{Al}_{2} \mathrm{O}_{3}$ combines maximum mass:

$$
\mathrm{CaSO}_{4} \cdot 2 \mathrm{H}_{2} \mathrm{O}=\frac{172}{102}=1.69 \text {. }
$$

Unit mass $\mathrm{Fe}_{2} \mathrm{O}_{3}$ combines maximum mass:

$$
\mathrm{CaSO}_{4} \cdot 2 \mathrm{H}_{2} \mathrm{O}=\frac{172}{160}=1.08
$$

Then unit mass CFBC ash hydration reaction needs unit mass $\mathrm{CaO}$ and $\mathrm{CaSO}_{4} \cdot 2 \mathrm{H}_{2} \mathrm{O}$ can be calculated by

$$
\begin{aligned}
& m \mathrm{CaO} \\
& \quad=a\left(1.12 \omega_{\mathrm{SiO}_{2}}+1.65 \omega_{\mathrm{Al}_{2} \mathrm{O}_{3}}+1.05 \omega_{\mathrm{Fe}_{2} \mathrm{O}_{3}}-\omega_{\mathrm{CaO}}\right), \\
& m \mathrm{CaSO}_{4} \cdot 2 \mathrm{H}_{2} \mathrm{O} \\
& \quad=a\left(1.69 \omega_{\mathrm{Al}_{2} \mathrm{O}_{3}}+1.08 \omega_{\mathrm{Fe}_{2} \mathrm{O}_{3}}-2.15 \omega_{\mathrm{SO}_{3}}\right) b .
\end{aligned}
$$

Notes. $\omega_{\mathrm{SiO}_{2}}, \omega_{\mathrm{Al}_{2} \mathrm{O}_{3}}, \omega_{\mathrm{Fe}_{2} \mathrm{O}_{3}}, \omega_{\mathrm{CaO}}$, and $\omega_{\mathrm{SO}_{3}}$ are mass fractions of all kinds of compounds in CFBC ash.

$a$ is $\mathrm{CFBC}$ ash hydration reaction ratio, $b$ is $\mathrm{CFBC}$ ash expansion ratio:

$$
\begin{aligned}
& a=\frac{\text { reacted CFBC ash }}{\text { total CFBC ash }} \\
& b=\frac{\mathrm{Al}_{2} \mathrm{O}_{3}, \mathrm{Fe}_{2} \mathrm{O}_{3} \text { in formation reaction of } \mathrm{AFt}}{\mathrm{Al}_{2} \mathrm{O}_{3}, \mathrm{Fe}_{2} \mathrm{O}_{3} \text { participate in reaction }} .
\end{aligned}
$$

According to the proportion of all kinds of oxides, the theoretical optimum proportion of CFBC ash and CS can be calculated by (7). According to the results of this experiment, the indexes $a$ and $b$ are proposed to take 0.25 and 1 , respectively.

3.3. Effect on CFBC Ash Stabilizing Soil by Mixing FGDG. Based on the optimum proportion of CFBC ash : CS $=8: 2$, discuss the optimum proportion of FGDG in soil stabilizer. The effect of FGDG on stabilized soil compressive strength can be revealed by changing the proportion of FGDG in stabilizer. As is shown in Table 3, there is an optimum proportion of FGDG in stabilizer, and the optimum proportion is $10 \%$ of stabilizer by weight. In this proportion, the stabilized soil compressive strength can increase to $2.12 \mathrm{MPa}$, twice of that without FGDG. After that, the stabilized soil compressive strength decreased with the increasing proportion of FGDG. 
Stabilized soil is usually formed by uniformly mixing loose and porous soil particle groups. In order to obtain the highest strength of stabilized soil, stabilizer should not only bind the loose soil particles, but also squeeze and fill the pores [9]. Active $\mathrm{SiO}_{2}$ in $\mathrm{CFBC}$ ash reacts with $\mathrm{Ca}(\mathrm{OH})_{2}$ to produce cementitious hydrates $\mathrm{CSH}$, which can bind the loose soil particles together, producing a certain strength in this process. Active $\mathrm{Al}_{2} \mathrm{O}_{3}$ and $\mathrm{Ca}(\mathrm{OH})_{2}$ react with $\mathrm{CaSO}_{4} \cdot 2 \mathrm{H}_{2} \mathrm{O}$ to form expansible hydrates AFt. The solid volume doubles during the formation of $\mathrm{AFt}$, so that the volume expansion squeezes and fills the pores efficiently, making the stabilized soil more compact and enhancing the strength further. If more proportion of expansible hydrates is added, the cementitious structure provided by CSH would be insufficient; therefore, AFt will produce greater expansion destroying the links between particles formed by $\mathrm{CSH}$, leading to the decrease of stabilized soil strength.

3.4. Engineering Application Feasibility of CFBC Ash Stabilizing Soil. As is shown in Table 3 in sample 3-1, when stabilizer total content is $10 \%$ and the ratio of CFBC ash: CS : FGDG $=7.2: 1.8: 1$, compressive strength of stabilized soil can reach the maximum of $2.12 \mathrm{MPa}$ at the age of $28 \mathrm{~d}$ of curing. Preliminary test results indicate that the hydration rate of $\mathrm{CFBC}$ ash is quite low, and the hydration ratio of CFBC ash at $90 \mathrm{~d}$ is two or three times that at $28 \mathrm{~d}$. It can be inferred that compressive strength of stabilized soil at 90 days will have greatly increased compared with that at $28 \mathrm{~d}$. Researches $[13,14]$ show that, in cement-soil mixing pile composite foundation and cement-soil mixing pile waterproof curtain, the compressive strength at $90 \mathrm{~d}$ is 0.5 to $1.5 \mathrm{MPa}$. This experiment shows that it is feasible to prepare soil stabilizer which is CFBC ash-based, supplemented with CS and FGDG, composed of complete industrial wastes.

CFBC ash hydration requires high water demand and low strength at early age; in particular, the free lime and anhydrite contained in CFBC ash can produce volume expansion during hydration, which severely limits the resource utilization of CFBC ash in concrete. However, all these characters will not be disadvantages if the $\mathrm{CFBC}$ ash is used in preparing soil stabilizer. The usage of soil stabilizer is mixing dry stabilizer powder or stabilizer mortar with soil. For mixing dry stabilizer powder with soil, high water requirement is beneficial to construction and increases strength. For mixing stabilizer mortar with soil, increment on water requirement, which will not bring significant effect on the compressive strength of stabilized soil, is quite little compared to soil's water content, according to the national technology standard, the standard compressive strength of stabilized soil should be taken at $90 \mathrm{~d}$; therefore, the low compressive strength of CFBC ash at early age is not a disadvantage. The volume expansion during hydration can just fill the pores in stabilized soil, which is beneficial to increase the compressive strength.

According to the preliminary test results obtained from this experiment and the analysis of the characteristics of $\mathrm{CFB}$ above, it is completely feasible to utilize CFBC ash to make the stabilizer. Stabilizer with better technical performance is expected to be made, which is CFBC ash-based and composed of complete industrial wastes, with further optimization.

\section{Conclusions}

(1) In this paper, stabilizers which are prepared by mixing $\mathrm{CS}$ with $\mathrm{CFBC}$ ash and PFA, respectively, are used to stabilize soil. The compressive strength of CFBC ash stabilizing soil is 3-5 times that of PFA stabilizing soil in the strength test at $28 \mathrm{~d}$, which shows that CFBC ash has better pozzolanic activity than fly ash.

(2) There is an optimum proportion of the ratio between CFBC ash and CS and the FGDG content. The compressive strength of stabilized soil peaks at $2.12 \mathrm{MPa}$ at the age of $28 \mathrm{~d}$, when total mixing proportion of stabilizer was $10 \%$ and $\mathrm{CFBC}$ ash : $\mathrm{CS}: \mathrm{FGDG}=7.2: 1.8: 1$. Using stabilizer which is CFBC ash-based, supplemented with CS and FGDG, composed of complete industrial wastes, can meet the engineering strength requirements.

\section{Conflict of Interests}

The authors declare that there is no conflict of interests regarding the publication of this paper.

\section{References}

[1] N. T. Dung, T.-P. Chang, and C.-T. Chen, "Engineering and sulfate resistance properties of slag-CFBC fly ash paste and mortar," Construction and Building Materials, vol. 63, pp. 40-48, 2014.

[2] T. Sebök, J. Šimoník, and K. Kulísek, "The compressive strength of samples containing fly ash with high content of calcium sulfate and calcium oxide," Cement and Concrete Research, vol. 31, no. 7, pp. 1101-1107, 2001.

[3] Y. Shen, J. Qian, and Z. Zhang, "Investigations of anhydrite in CFBC fly ash as cement retarders," Construction and Building Materials, vol. 40, pp. 672-678, 2013.

[4] D. C. Adriano, A. L. Page, A. A. Elseewi, A. C. Chang, and I. Straughan, "Utilization and disposal of fly ash and other coal residues in terrestrial ecosystems: a review," Journal of Environmental Quality, vol. 9, no. 3, pp. 333-344, 1980.

[5] X. Huang, Z. Li, J. Ning, and S. Xu, "Principle and method of optimization design for soft soil stabilizer," Journal Wuhan University of Technology-Materials Science Edition, vol. 24, no. 1, pp. 154-160, 2009.

[6] E. Mulder, "A mixture of fly ashes as road base construction material," Waste Management, vol. 16, no. 1-3, pp. 15-20, 1996.

[7] G. Thenoux, F. Halles, A. Vargas, J. P. Bellolio, and H. Carrillo, "Laboratory and field evaluation of fluid bed combustion fly ash as granular road stabilizer," Transportation Research Record, vol. 2, no. 1989, pp. 36-41, 2007.

[8] N. M. Jackson, R. Mack, S. Schultz, and M. Malek, "Pavement subgrade stabilization and construction using bed and fly ash," in Proceedings of the World of Coal Ash Conference (WOCA '07), pp. 7-10, Lexington, Ky, USA, May 2007.

[9] H. Xin, N. Jianguo, and X. Sheng, "Structure formation model of stabilized soil," Industrial Construction, vol. 36, no. 7, pp. 1-6, 2006. 
[10] D.-W. Zhang and Z.-G. Cao, "Strength characteristics of stabilized soils using industrial by-product binders," Rock and Soil Mechanics, vol. 34, no. 1, pp. 54-59, 2013.

[11] P. Chindaprasirt and U. Rattanasak, "Utilization of blended fluidized bed combustion (FBC) ash and pulverized coal combustion (PCC) fly ash in geopolymer," Waste Management, vol. 30, no. 4, pp. 667-672, 2010.

[12] Y. Song, J. Qian, and Z. Wang, "Pozzolanic reactivity of coal ashes," Journal of the Chinese Ceramic Society, vol. 34, no. 8, pp. 962-965, 2006.

[13] Engineering Project of Foundation Treatment, China Architecture \& Building Press, 1998.

[14] G. Xiaonan, Foundation Treatment Manual, China Architecture \& Building Press, Beijing, China, 2008. 

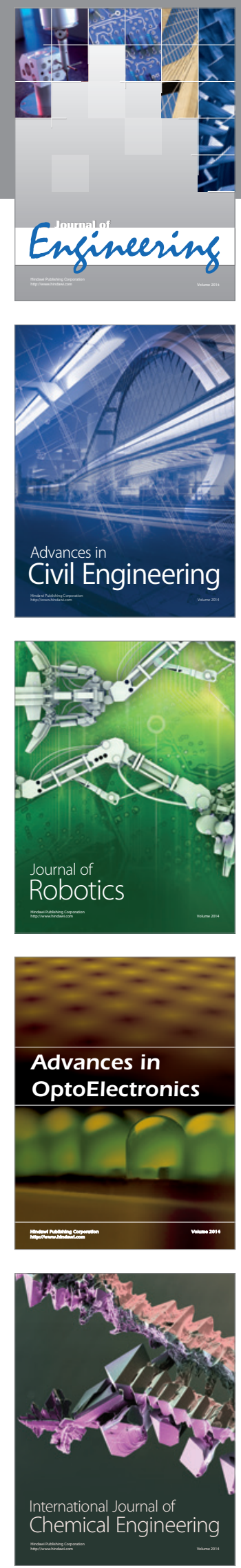

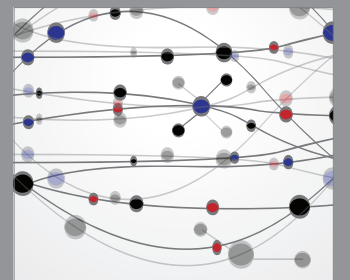

The Scientific World Journal
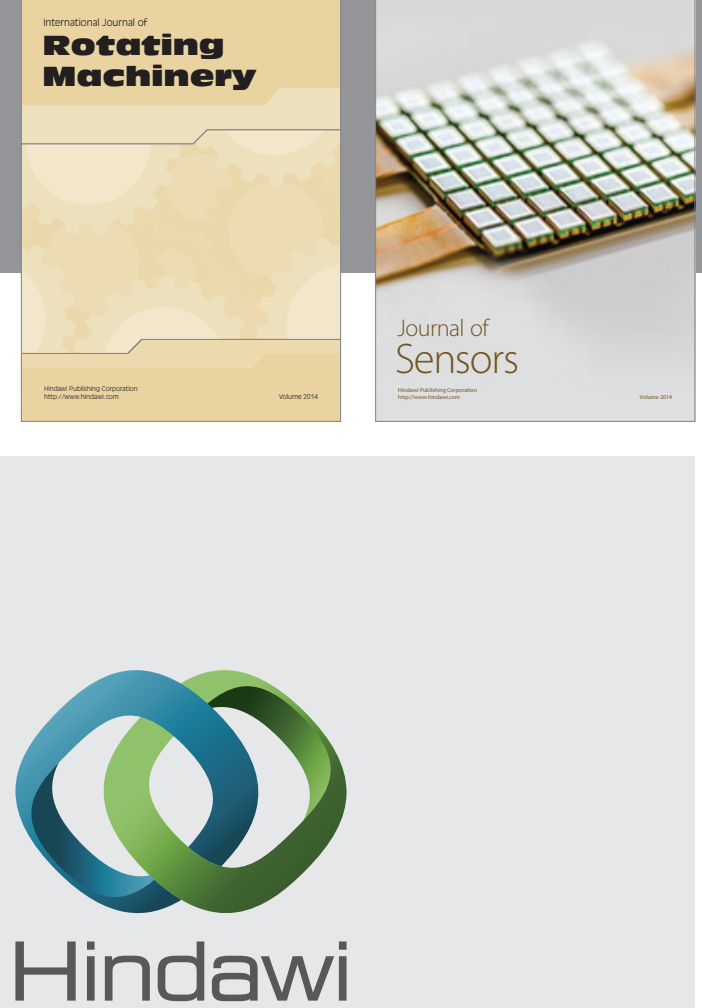

Submit your manuscripts at http://www.hindawi.com
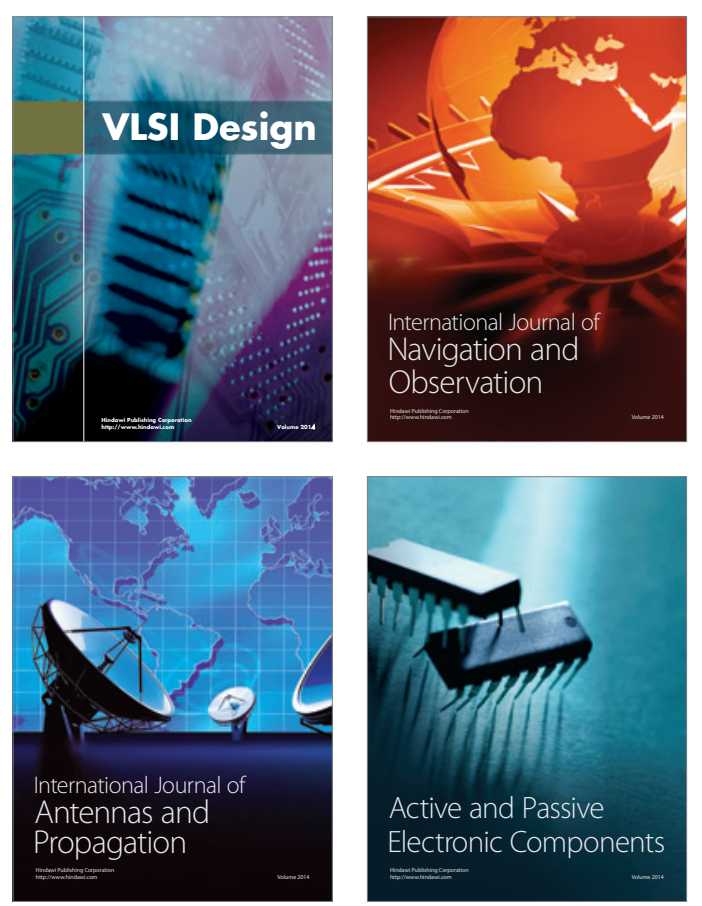
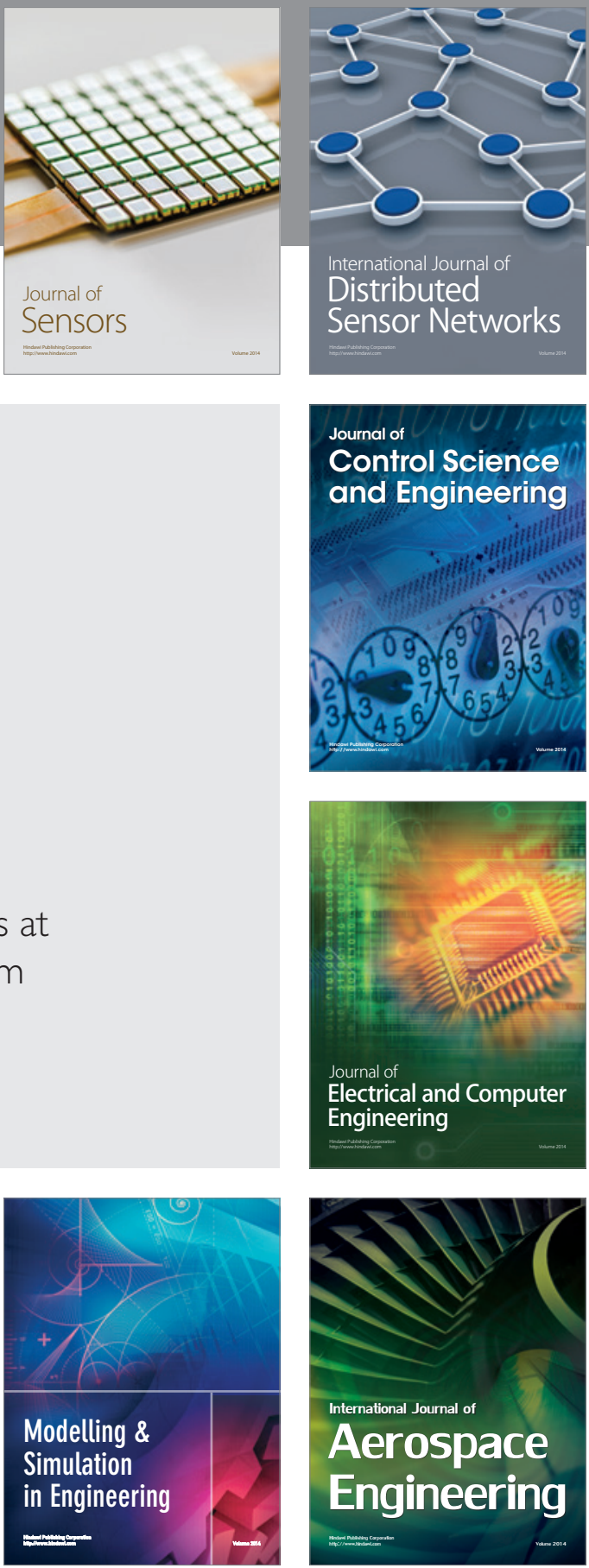

Journal of

Control Science

and Engineering
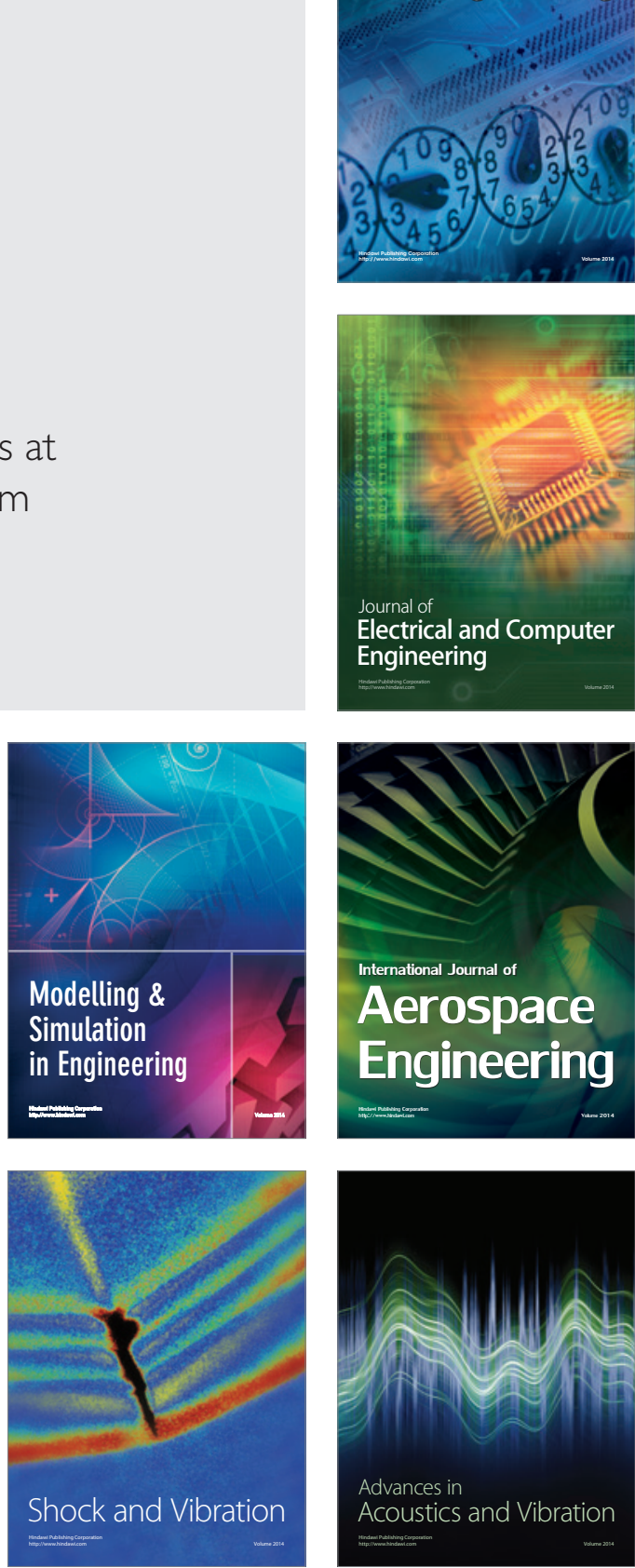